\title{
Response of Sitotroga cerealella (Olivier) and Trichogramma chilonis (Ishii) towards chilling temperature
}

Jawad Sarwar ${ }^{1 *}$, Imtiaz Ali Khan ${ }^{1}$, Fazli Amin ${ }^{1}$, Hafiz Muhammad Faisal Ayub $^{2}$ and Amjad Usman ${ }^{1}$

1. Department of Entomology, The University of Agriculture, Peshawar-Pakistan

2. Agricultural Research Station, Swabi, Swabi-Pakistan

*Corresponding author's email: jawadsarwar@aup.edu.pk

Citation

Jawad Sarwar, Imtiaz Ali Khan, Fazli Amin, Hafiz Muhammad Faisal Ayub and Amjad Usman. Response of Sitotroga cerealella (Olivier) and Trichogramma chilonis (Ishii) towards chilling temperature. Pure and Applied Biology. Vol. 9, Issue 2, pp1504-1509. http://dx.doi.org/10.19045/bspab.2020.90156

\begin{tabular}{llll}
\hline \hline Received: 29/11/2019 & Revised: 28/02/2020 & Accepted: 04/03/2020 & Online First: 13/03/2020
\end{tabular}

\section{Abstract}

Studies were conducted to evaluate the impact of storability of $S$. cerealella and $T$. chilonis at zero and control temperature for different time interval i.e. $(2,6,12$, and 24) h. Research reveals that different tem, time interval effect the parameters like incubation, emergence, hatching and longevity. Three different sets of experiments were conducted to observe hatching $(\%)$ and incubation period of $S$. cerealella, emergence (\%) and adult longevity of $T$. chilonis from parasitized pupae and parasitism of S. cerealella eggs, subsequent emergence $(\%)$ of $T$. chilonis from the parasitized eggs and their adult longevity. Interpretation of findings unravels that eggs stored for shorter period of time i.e. 2 hours resulting in higher hatching $(85.33 \%)$ and incubation period (8.13 days). Higher pupal emergence $(82.66 \%)$ of $T$. chilonis and adult longevity (6.23 days) for storage period of 2 hours and an increase in duration decline was recorded. Significantly higher parasitism $(86.66 \%)$ of $S$. cerealella, emergence $(92.71 \%)$ and adult longevity $(6.13$ days) was recorded for storage period of 2 hours and with increase in duration the declension was recorded in parameters under study.

Keywords: Adult longevity; Chilling temperature; Emergence (\%); Incubation period; Parasitism

\section{Introduction}

Trichogramma chilonis is an important egg parasitoid used for the management of sugarcane borer, Diatraea saccharalis (Fabricius) [1]. Rearing of T. chilonis is important for continuous supply of parasitoids, mass rearing of this parasitoid is facilitated by $S$. cereallela. This moth can easily be reared on wheat or other grains [2, 3].

Large scale rearing of $T$. chilonis is parallel with various factors such as temperature, photoperiod, relative humidity and quality of host's eggs. Productivity and host acceptance of the wasp is effected by egg size and newly emerged wasp [4]. Effectiveness of $T$. chilonis may vary due to various abiotic factors [5]. Frequent change in the climatic conditions particularly in temperature, constitute an environment difficult for the insect to adapt [6]. Host age of the moth greatly affects the parasitization rate of parasitoid in two different ways, firstly preference of parasitoid female for oviposition and secondly indication of resource quality available for developing parasitoid larvae $[7,8]$. 
To improve egg parasitoid rearing and increased supply of $T$. chilonis, chilled host eggs have also been used and stored under chilled conditions for longer period and continuous supply of host eggs [9]. Host eggs are exposed to super cooling temperature particularly below freezing point $\left(0^{\circ} \mathrm{C}\right)$ that supported survival at later stages of egg development than fresh eggs [10]. Different scientists [11-13] have observed the impact of cold storage on parasitism of $T$. chilonis. Purpose of the study was to observe the impact of chilled temperature on $S$. cerealella eggs and T. chilonis pupae.

\section{Materials and methods}

To observe the effect of low temperature on $S$. cerealella and $T$. chilonis a study was conducted at bio-control lab of department of Entomology during 2016. S. cerealella and T. chilonis were reared as described by [14]. Three different experiments were conducted which are elaborated as follow:

\section{Effect of low temperature on $S$. cerealella} eggs

Twelve and 24 hours old batches of 50 fresh eggs of $S$. cerealella were pasted on cards and placed in an incubator at $0^{\circ} \mathrm{C}$ along with control, each for different time intervals $(2,4$, 6 and 8) hours. Experiment was replicated three times and data of hatching (\%) and hatching duration (incubation period) were recorded. Design used was factorial CRD.

Effect of low temperature on pupae of $T$. chilonis

Batches of 50 fresh pupae of $T$. chilonis were placed in an incubator at $0^{\circ} \mathrm{C}$ and a control for different time intervals $(2,4,6$ and 8) hours. For each temperature the experiment was replicated three times. Data of percent adult emergence and adult longevity were recorded. Design used was factorial CRD.

Effect of low temperature on $S$. cerealella eggs and subsequent effect on emerging $T$. chilonis

In this experiment (12 and 24) hours old batches of 50 fresh of eggs each of $S$. cerealella were pasted on cards and placed in an incubator at $0^{\circ} \mathrm{C}$ and a control for different time interval (2, 4, 6 and 8) hours. After that the same eggs of $S$. cerealella were exposed to two fresh pairs of $T$. chilonis for parasitization. Data of $\%$ parasitism, adult emergence and adult longevity were recorded. Design used was factorial CRD.

\section{Results and discussion}

Effect of low temperature on hatching (\%) and incubation period of $S$. cerealella

Data regarding hatching (\%) and incubation period of $S$. cerealella is presented in (Table 1) which revealed that egg age (h), temperature $\left({ }^{\circ} \mathrm{C}\right)$ and storage period $(\mathrm{h})$ had significantly affected hatching and incubation period. Twelve hours aged eggs of $S$. cerealella had significantly higher hatching $(\%)(85.33 \%)$ and incubation period (8.13 days) for eggs stored for 2 hours, while lower hatching (\%) $(47.33 \%)$ and incubation period (6.10 days) was recorded for eggs stored for 8 hours. Similarly, for $24 \mathrm{~h}$ aged eggs of $S$. cerealella significantly higher hatching $(80.66 \%)$ and incubation period (6.06 days) was recorded for eggs stored for 2 hours, while lower hatching $(44.66 \%)$ and incubation period (4.96 days) was recorded for eggs stored for 8 hours. In control, hatching of $S$. cerealella eggs was significantly higher than all the treatments for both $12 \mathrm{~h}$ and $24 \mathrm{~h}$ aged eggs stored for $(2 \mathrm{~h})$ and lowest $(0.00 \%$ each) for $(4,6$, and $8 \mathrm{~h})$ stored eggs, though control yielded lower incubation period in relation to 12 and $24 \mathrm{~h}$ old eggs. It is evident from the table chilling temperature can be effective for shorter duration and as the duration is increased there is a decrease in hatching (\%) and incubation period, also $12 \mathrm{~h}$ aged eggs are more productive in comparison to $24 \mathrm{~h}$ aged eggs in respect to the studied parameters. However pattern of hatching (\%) and incubation period is quite similar in both (12 and 24h) aged eggs. Our findings are in agreement to [15] they observed the impact of chilling $\left(\right.$ at $-1^{\circ} \mathrm{C}$ ) 
on eggs of $S$. cerealella at different duration of time and noted that higher hatching (\%) was for eggs stored till $2 \mathrm{~h}(81.2 \%)$ and with the increase in storage duration hatching declined to $0.8 \%$ for $72 \mathrm{~h}$ period of storage.
[16] also stored eggs of Rhyzopertha dominica on low temperature and found out that with increase in storage duration higher mortality was reported.

Table 1. Effect of low temperature on hatching (\%) and incubation period of $S$. cerealella eggs

\begin{tabular}{|c|c|c|c|c|c|c|c|c|}
\hline \multirow{2}{*}{$\begin{array}{c}\text { Storage } \\
\text { Period } \\
\text { (Hours) }\end{array}$} & \multicolumn{4}{|c|}{ Hatching \% } & \multicolumn{4}{|c|}{ Incubation Period } \\
\hline & $12 \mathrm{~h}$ & (Control) & $24 \mathrm{~h}$ & (Control) & $12 \mathrm{~h}$ & (Control) & $24 h$ & (Control) \\
\hline 2 & $85.33 b$ & $90.00 \mathrm{a}$ & $80.66 \mathrm{c}$ & $87.33 \mathrm{~b}$ & $8.13 \mathrm{a}$ & $3.10 \mathrm{f}$ & $6.06 \mathrm{c}$ & $6.06 \mathrm{c}$ \\
\hline 4 & $72.00 \mathrm{~d}$ & $0.00 \mathrm{i}$ & $68.00 \mathrm{e}$ & $0.00 \mathrm{i}$ & $7.10 \mathrm{~b}$ & $0.00 \mathrm{~g}$ & $4.96 \mathrm{~d}$ & $0.00 \mathrm{~g}$ \\
\hline 6 & $62.66 \mathrm{f}$ & $0.00 \mathrm{i}$ & $62.66 \mathrm{f}$ & $0.00 \mathrm{i}$ & $7.06 \mathrm{~b}$ & $0.00 \mathrm{~g}$ & $4.06 \mathrm{e}$ & $0.00 \mathrm{~g}$ \\
\hline 8 & $47.33 \mathrm{~g}$ & $0.00 \mathrm{i}$ & $44.66 \mathrm{~h}$ & $0.00 \mathrm{i}$ & $6.10 \mathrm{c}$ & $0.00 \mathrm{~g}$ & $4.96 \mathrm{~d}$ & $0.00 \mathrm{~g}$ \\
\hline $\begin{array}{c}\text { LSD } \\
\text { Value }\end{array}$ & \multicolumn{4}{|c|}{2.54} & \multicolumn{4}{|c|}{0.18} \\
\hline
\end{tabular}

Effect of low temperature on emergence and adult longevity of Trichogramma chilonis

Data illustrated in (Table 2) shows that temperature $\left({ }^{\circ} \mathrm{C}\right)$ and storage period $(\mathrm{h})$ had significantly different effect on emergence (\%) and adult longevity of $T$. chilonis from pupae. Significantly higher emergence $(82.66 \%)$ and adult longevity (6.23 days) of T. chilonis was recorded for pupae stored for 2 hours, and lower emergence (38\%) and adult longevity (3.16 days) for pupae stored for 8 hours. In control, emergence (\%) and adult longevity was significantly higher than all the treatments i.e. $(88.66 \%)$ and $(7.16$ days) for $2 \mathrm{~h}$ stored pupae and lowest $(0.00 \%$, each) for 4, 6 and $8 \mathrm{~h}$ pupae. It is evident from (Table 2) that pupae stored for shorter interval results in higher emergence $(\%)$ and with increase in time of storage emergence declined. Also control recorded higher emergence $(\%)$ as compare to all storage periods. Our findings on decreased adult longevity at $8^{\circ} \mathrm{C}$ for prolonging storage are pertinent with the study reported by [17], where adult longevity of egg parasitoid $T$. cacoeciae was decreased after 31 days storage at $8^{\circ} \mathrm{C}$. [18] exemplified the storage temperatures lower than $10^{\circ} \mathrm{C}$ and storage times 3 week or longer had a negative impact on longevity. Our study is also in coherence with that of [19] who studied that acclimation for 30 days at $10^{\circ} \mathrm{C}$ or 24 days at $13^{\circ} \mathrm{C}$ allowed $T$. brassicae immatures to develop with a lower mortality than those exposed directly at $5^{\circ} \mathrm{C}$. Longevity and fecundity of females decreased at a lower rate with acclimation at $10{ }^{\circ} \mathrm{C}$ suggesting that acclimation at $13^{\circ} \mathrm{C}$ may have depleted the energy reserves of individuals more than acclimation at $10^{\circ} \mathrm{C}$.

Effect of low temperature on parasitism of Sitotroga cerealella and subsequent emergence and adult longevity of $T$. chilonis

Data contained in (Table 3) shows that egg age $(\mathrm{h})$, temperature $\left({ }^{\circ} \mathrm{C}\right)$ and storage period (h) had significantly different effect on parasitism (\%) of S. cerealella eggs and subsequent emergence $(\%)$ and adult longevity of $T$. chilonis. For $12 \mathrm{~h}$ aged eggs of $S$. cerealella significantly higher parasitism $(86.66 \%)$, emergence $(92.71 \%)$ and adult longevity (6.13 days) was recorded for eggs stored for 2 hours and lower parasitism (54\%), emergence (77.88\%) and adult longevity (4.10 days) was recorded for eggs stored for 8 hours. Similarly, for $24 \mathrm{~h}$ aged 
eggs of $S$. cerealellahigher parasitism (91.33\%), emergence $(81.54 \%)$ and adult longevity (5.20 days) was recorded for eggs stored for 2 hours and lower parasitism $(34.66 \%)$, emergence $(80.16 \%)$ and adult longevity (3.10 days) was recorded for eggs stored for 8 hours. In control, parasitism (\%) of $S$. cerealella eggs and emergence (\%) and adult longevity of $T$. chiloniswas significantly higher than all the treatments for both $12 \mathrm{~h}$ and $24 \mathrm{~h}$ aged eggs stored till 2 hours and lower $(0.00 \%$, each) for 4,6 and 8 hoursstored eggs. From these findings it is clear that adult of $T$. chilonis had a better approach of parasitism towards $12 \mathrm{~h}$ old eggs stored for short interval of time in comparison to $24 \mathrm{~h}$ old eggs stored for similar duration.Our findings are also co-related to [15] they reported the parasitism of $24 \mathrm{~h}$ old eggs $S$. cerealella by $T$. chilonis and found that maximum parasitism of $49 \%$ for $2 \mathrm{~h}$ stored eggs and less than $2 \%$ for $72 \mathrm{~h}$ storage period at chilling temperature. [9] also observed that parasitism is affected by host eggs age and storage period. Eggs stored for short interval results in higher parasitism and while eggs stored for longer period results in low parasitism which may be due to the deformity of embryo.

Table 2. Effect of low temperature on emergence and adult longevity of Trichogramma chilonis

\begin{tabular}{|c|c|c|c|}
\hline Temperatures $\left({ }^{\mathbf{0}} \mathbf{C}\right)$ & Storage Period $(\mathbf{h})$ & Emergence $(\boldsymbol{\%})$ & Adult Longevity (days) \\
\hline \multirow{3}{*}{0} & 2 & $82.66 \mathrm{~b}$ & $6.23 \mathrm{~b}$ \\
\cline { 2 - 4 } & 4 & $66.00 \mathrm{c}$ & $5.03 \mathrm{c}$ \\
\cline { 2 - 4 } & 6 & $51.66 \mathrm{~d}$ & $4.10 \mathrm{~d}$ \\
\cline { 2 - 4 } & 8 & $38.00 \mathrm{e}$ & $3.16 \mathrm{e}$ \\
\hline \multirow{3}{*}{$25($ Control) } & 2 & $88.66 \mathrm{a}$ & $7.10 \mathrm{a}$ \\
\cline { 2 - 4 } & 4 & $0.00 \mathrm{f}$ & $0.00 \mathrm{f}$ \\
\cline { 2 - 4 } & 6 & $0.00 \mathrm{f}$ & $0.00 \mathrm{f}$ \\
\cline { 2 - 4 } & 8 & $0.00 \mathrm{f}$ & $0.00 \mathrm{f}$ \\
\hline LSD Value & & 2.80 & 0.18 \\
\hline
\end{tabular}

Table 3. Effect of low temperature on parasitism of sitotroga cerealella and subsequent emergence and adult longevity of $T$. chilonis

\begin{tabular}{|c|c|c|c|c|c|c|c|c|c|c|c|c|}
\hline \multirow{2}{*}{$\begin{array}{c}\text { Storage } \\
\text { Period } \\
\text { (Hours) }\end{array}$} & \multicolumn{4}{|c|}{ Parasitism \% } & \multicolumn{4}{|c|}{ Emergence \% } & \multicolumn{4}{|c|}{ Adult Longevity (days) } \\
\hline & $12 \mathrm{~h}$ & (Control) & $24 \mathrm{~h}$ & (Control) & $12 \mathrm{~h}$ & (Control) & $24 h$ & (Control) & $12 \mathrm{~h}$ & (Control) & $24 \mathrm{~h}$ & (Control) \\
\hline 2 & $\begin{array}{c}86.66 \\
\text { b }\end{array}$ & $91.33 \mathrm{a}$ & $\begin{array}{c}61.33 \\
\mathrm{~d}\end{array}$ & $90.66 \mathrm{a}$ & $\begin{array}{c}92.71 \\
\mathrm{a}\end{array}$ & $94.85 \mathrm{a}$ & $\begin{array}{c}87.33 \\
b\end{array}$ & $95.61 \mathrm{a}$ & $\begin{array}{c}6.13 \\
\mathrm{c}\end{array}$ & $8.10 \mathrm{a}$ & $\begin{array}{c}5.20 \\
d\end{array}$ & $7.13 \mathrm{~b}$ \\
\hline 4 & $\begin{array}{c}82.00 \\
\mathrm{c}\end{array}$ & $0.00 \mathrm{~g}$ & $\begin{array}{c}51.33 \\
\mathrm{e}\end{array}$ & $0.00 \mathrm{~g}$ & $\begin{array}{c}89.24 \\
\text { b }\end{array}$ & $0.00 \mathrm{f}$ & $\begin{array}{c}81.54 \\
\text { cd }\end{array}$ & $0.00 \mathrm{f}$ & $\begin{array}{c}6.13 \\
c\end{array}$ & $0.00 \mathrm{~g}$ & $\begin{array}{c}4.10 \\
\mathrm{e}\end{array}$ & $0.00 \mathrm{~g}$ \\
\hline 6 & $\begin{array}{c}64.00 \\
\mathrm{~d}\end{array}$ & $0.00 \mathrm{~g}$ & $\begin{array}{c}36.66 \\
\text { f }\end{array}$ & $0.00 \mathrm{~g}$ & $\begin{array}{c}83.38 \\
\mathrm{c}\end{array}$ & $0.00 \mathrm{f}$ & $\begin{array}{c}80.50 \\
\text { cde }\end{array}$ & $0.00 \mathrm{f}$ & $\begin{array}{c}5.13 \\
d\end{array}$ & $0.00 \mathrm{~g}$ & $\begin{array}{c}3.13 \\
\mathrm{f}\end{array}$ & $0.00 \mathrm{~g}$ \\
\hline 8 & $\begin{array}{c}54.00 \\
\mathrm{e}\end{array}$ & $0.00 \mathrm{~g}$ & $\begin{array}{c}34.66 \\
\mathrm{f}\end{array}$ & $0.00 \mathrm{~g}$ & $\begin{array}{c}77.88 \\
\mathrm{e}\end{array}$ & $0.00 \mathrm{f}$ & $\begin{array}{c}80.16 \\
\text { de }\end{array}$ & $0.00 \mathrm{f}$ & $\begin{array}{c}4.10 \\
\mathrm{e}\end{array}$ & $0.00 \mathrm{~g}$ & $\begin{array}{c}3.10 \\
\mathrm{f}\end{array}$ & $0.00 \mathrm{~g}$ \\
\hline $\begin{array}{c}\text { LSD } \\
\text { Value }\end{array}$ & \multicolumn{4}{|c|}{2.79} & \multicolumn{4}{|c|}{3.20} & \multicolumn{4}{|c|}{0.20} \\
\hline
\end{tabular}

\section{Conclusion and recommendation}

It is concluded from the experiment that storage of S. cerealella eggs and T. chilonis pupae at low temperature for shorter interval provided efficient results. All the parameters under observation yielded encouraging 
results when observed for short duration of time. It is recommended to store $S$. cerealella eggs and T. chilonis pupae at $0^{\circ} \mathrm{C}$ for shorter duration so we can have the population of $\mathrm{T}$. chilonis available round the year for biological control programs.

\section{Author's contributions}

Conceived and designed the experiments: J Sarwar \& IA Khan, Performed the experiments: J Sarwar \& A Usman, Analyzed the data: F Amin \& HMF Ayub, Wrote the paper: J Sarwar.

\section{References}

1. Ashraf M \& Fatima B (1993). Control of sugarcane borers by inundative releases of Trichogramma chilonis (Ishii). Pak J Zool 25: 23-25

2. Flanders SE (1930). Mass production of egg parasites of genus Trichogramma. Hilgardia 4: 465-501.

3. Hassan SA (1988). Selection of suitable Trichogramma strains to control the codling moth Cydia pomonella and the two summer fruit tortrix moths Adoxophyes orana, Pandemis heparana (Lep.: Tortricidae). Entomophaga 33(4): 19-27.

4. Greenberg SM, Morrison RK, Nordlund D \& King EG (1998). A review of the scientific literature and methods for production of factitious hosts for use in mass rearing of Trichogramma spp. (Hymenoptera: Trichogrammatidae) in the former Soviet Union, the United States, Western Europe and China. $J$ Entomol Sci 33(1): 15-32.

5. Hoffmann MP, Ode PR, Walker DL, Gardner J, Van Nouhuys S \& Shelton AM (2001). Performance of Trichogramma ostriniae (Hymenoptera: Trichogram-matidae) reared on factitious hosts, including the target host, Ostrinia nubilalis (Lepidoptera: Crambidae). Biol Control 21(1): 1-10.

6. Hassan SA (1994). Strategies to select Trichogramma species for the use in biological control. $C A B$ Inter, $U K$ 4(1): 55-73.

7. Vinson SB (1985). The behavior of parasitoids. In: Comprehensive Insect Physiology, Biochemistry and Pharmacology (Kerkut GA, Gilbert LI, eds), Pergamon Press, Oxford, UK. 417469.

8. Farid A, Saqib T \& Khan AU (2001). Host age effect on oviposition preference and development of Trichogramma chilonis. Pak J Biol Sci 4(2): 121-122.

9. Mona BR \& Mandarawy EI (2003). Suitability of Ephestia kuehniella (Zeller) (Pyralidae: Lepidoptera) eggs for parasitization by Trichogramma evanescens West and Trichogramma cacoeciae Marchal (Trichogrammatidae: Hymenoptera). Pak J Biol Sci 6(16): 1459-1462.

10. Drooze AT \& Weems ML (1982). Cooling eggs of Eutrapela clemataria (Lepidoptera: Geometridae) to $-10 \mathrm{c} 0$ forestalls decline in parasite production with Ooencyrtus ennmophagus (Hymenoptera: Formicidae). Can Entomol 114: 1195-1195.

11. $\mathrm{Hu} \mathrm{ZW} \& \mathrm{Xu}$ QY (1988). Studies on frozen storage of eggs of rice moth and oak silkworm. Collques-de-1'INRA 43: 327-338.

12. Hugar P, Rao KJ \& Lingappa S (1990). Effect of chilling on hatching and parasitism of eggs of Corcyra cephalonica Stainton by $T$. chilonis (Ishii). Entomol 15: 49-52.

13. Burks CS, Hagstrum DW, Hampton KE \& Broce AB (1997). Crystallization temperature and chilling injury during over wintering in a feral face fly (Diptera: Muscidae) population. Environ Entomol 26: 1112-1130.

14. Nadeem S, Ashfaq M, Hamed M \& Sohail A (2010). Optimization of Short and Long Term Storage Duration for Trichogramma chilonis (Ishii) 
(Hymenoptera: Trichogrammatidae) at Low Temperatures. Pak J Zool 42(1): 63-67.

15. Muhammad R, Qadeer A, Rashidi A \& Nazir (2013). Role of Irradiated and Chilled Host Sitotroga cerealella Eggs to Enhance the Parasitic Potential of Egg Parasitoid Trichogramma chilonis (Ishii). Acad J Entomol 6(3): 133-138.

16. Mbata GN, Phillips TW \& Payton M (2004). Mortality of Eggs of StoredProduct Insects Held Under Vacuum: Effects of Pressure, Temperature, and Exposure Time. J Econ Entomol 97(2): 1695-1702.

17. Özder N (2004). Effect of different cold storage periods on parasitization performance of Trichogramma cacoeciae (Hymenoptera,
Trichogrammatidae) on eggs of Ephestia kuehniella (Lepidoptera, Pyralidae). Biocon Sci Technol 14(5): 441-447.

18. Rundle BJ, Thomson LJ \& Hoffmann AA (2004). Effects of cold storage on field and laboratory performance of Trichogramma carverae (Hymenoptera: Trichogrammatidae) and the response of three Trichogramma spp. (T. carverae, T. brassicae and T. funiculatum) to cold. J Econ Entomol 97: 213-221.

19. Vigneswaran S, Jethva DM, Wadaskar PS \& Balas TK (2017). Effect of Cold Temperature Durations on the Emergence and Parasitization Efficiency of Laboratory Reared Trichogramma chilonis (Ishii). Int J Curr Microbiol Appl Sci 6(5): 1191-1199. 